\title{
Revive Negócio, uma plataforma para impulsionar ideias e startups no ecossistema de inovação do Ceará
}

\author{
Matheus F. de Oliveira ${ }^{1}$, Renato A. C Freitas ${ }^{1}$, Sílvio R. Evangelista, \\ Henrique V. Oliveira ${ }^{1}$, Cairamir Arruda ${ }^{3}$, Francisco S. Júnior $^{2}$, \\ Antônio Mauro B. Oliveira ${ }^{1}$
}

\author{
${ }^{1}$ Instituto Federal de Educação, Ciência e Tecnologia do Ceará, campus Aracati \\ ${ }^{2}$ Instituto Federal de Educação, Ciência e Tecnologia do Ceará, campus Fortaleza \\ ${ }^{3}$ Secretaria do Desenvolvimento Econômico e Trabalho \\ \{matheusferreiradeoliveira21, drsilvioramos, \}@gmail.com \\ \{henrique.viana.oliveira, jwebsys, amauroboliveira\}@gmail.com \\ renato.freitaseppgcc.ifce.edu.br \\ cairamir.arruda@sedet.de.gov.br
}

\begin{abstract}
This work presents Revive Negócios, a platform associated with a methodology for registering and boosting ideas and startups, with a focus on economic recovery. The platform implementation and the specification of the seven-level methodology are described. At Revive Negócios, the registered idea and startup are carefully analyzed, receive the appropriate technical and management advice, support in the business model and market share, etc., for the composition of the ecosystem of innovation and socioeconomic improvement in the State. Revive Negócios is already operational, the result of a partnership between Iracema Digital, the Federal Institute of Ceará(IFCE), Aracati Digital, APSV Advogados and the Government of Ceará.
\end{abstract}

Resumo. Este trabalho apresenta o Revive Negócio, uma plataforma associada a uma metodologia para o cadastro e impulsionamento de ideias e de startups, com foco na retomada da economia. São descritas a implementação da plataforma e a especificação de uma metodologia de sete níveis. No Revive Negócio a ideia e a startup cadastradas são criteriosamente analisadas, recebem os devidos aconselhamentos técnicos e de gestão, apoio no modelo de negócio e participação no mercado, etc., para composição do ecossistema de inovação e melhoria socioeconômica do Estado. O Revive Negócio já se encontra operacional, resultado de uma parceria entre o Iracema Digital, o Instituto Federal do Ceará (IFCE), o Aracati Digital, a APSV Advogados e o Governo do Ceará.

\section{Introdução}

A pandemia da COVID-19 vem causando graves problemas em várias áreas, em especial na saúde, na educação e na economia. A saúde está sendo a área mais afetada, com a internação e óbito de milhões de pessoas em todo o mundo ${ }^{1}$, além das complicações

\footnotetext{
${ }^{1}$ Fonte: https://covid19.who.int/
} 
de saúde mental, como o surgimento de transtornos psicológicos, e das complicações físicas, como a má alimentação e ganho de peso, apresentadas por milhões de pessoas [Ho et al. 2020]. Na educação, o bloqueio das atividades presenciais nas escolas, creches e universidades tem atingido milhares de estudantes e tem impactado no nível de ensino e aprendizagem nas instituições em todo o mundo [PASINI et al. 2020]. Na economia, as consequências têm sido severas devido ao fechamento parcial e/ou total do comércio, levando à falência ou a inatividade de diversas empresas. Com o bloqueio de mercados e de viagens nacionais/internacionais, muitas empresas de vendas e turismo enfrentam grandes quedas em suas vendas e ações e declararam falência [DA COSTA 2020].

Como resposta à essa crise, várias propostas metodológicas nacionais de enfrentamento à COVID-19 foram criadas nas diversas áreas. Na área da saúde vale destacar o movimento "Um milhão de máscaras" ${ }^{2}$ uma iniciativa coletiva com o objetivo de construir uma rede para produzir e distribuir máscaras em hospitais, asilos, comunidades e ao público geral. Na educação, o aplicativo Remoto ${ }^{3}$ da startup Outra Coisa foca em familiarizar os usuários com as melhores práticas do trabalho remoto utilizando uma metodologia de gamificação. O aplicativo acompanha o progresso dos usuários enquanto disponibiliza quizzes e textos. Este material estimula o usuário a pensar em sua organização e na comunicação com o resto de sua equipe em diversas situações. No contexto da retomada da economia, um bom exemplo é o aplicativo Simbio $\mathrm{Bag}^{4}$, desenvolvido para auxiliar varejistas de moda no envio de mercadorias personalizadas para seus clientes, evitando a necessidade do cliente de ir até a loja para experimentar produtos. Durante a pandemia, a startup responsável disponibilizou uma versão gratuita da aplicação. Ainda na economia, outro bom exemplo é a plataforma FiqueNoLar ${ }^{5}$ do IFCE, uma ferramenta para facilitar a divulgação dos estabelecimentos que prestam serviços em casa, que fazem entregas em domicílio ou que oferecem serviços de retiradas de produtos.

Nota-se, porém, que muitas ideias para a retomada da economia são produzidas por empreendedores, startups e empresas de pequeno e médio porte que, geralmente, enfrentam dificuldades relacionadas a divulgação, publicidade e marketing. Além disso, as instituições tradicionais de financiamento requerem garantias muitas vezes inviáveis para pequenos empreendimentos [Hervé and Schwienbacher 2018]. Dessa forma, muitos projetos e ideias em estado inicial acabam reservadas apenas a redes sociais ou ao escopo de instituições públicas e privadas, fora do alcance de muitos interessados, clientes e empreendedores. Assim, um repositório de ideias e startups com foco na retomada da economia auxilia na problemática da divulgação e pode se tornar uma ferramenta útil para impulsionar essas ideias e startups a consolidarem seus propósitos.

Este trabalho apresenta a especificação e a implementação do Revive Negócio, uma plataforma que permite o cadastro de ideias e startups capazes de mitigar os problemas na economia, advindos da epidemia da COVID-19. Seu objetivo inicial é impulsionar idealizadores de ideias e de startups a cadastrarem produtos, protótipos, processos metodológicos, etc. de diversas áreas: saúde, economia, educação, comunicação, tecnologia, etc.

\footnotetext{
${ }^{2}$ Fonte: https://www.ummilhaodemascaras.com.br/

${ }^{3}$ https://remoto.joco.com.br/

${ }^{4}$ Disponível em: https://www.simbiobag.com/br/

${ }^{5}$ Disponível em: https://www.fiquenolar.ifce.edu.br/
} 
A plataforma Revive Negócio possui uma metodologia original com sete níveis. Esse trabalho propõe uma alteração na atual metodologia, adicionando funcionalidades de crowdfunding para aumentar o acervo de possibilidades de investimentos para as ideias e startups cadastradas na plataforma. Dessa forma, o Revive Negócio facilita a obtenção de investimentos e disponibiliza funcionalidades para desenvolver as ideias e startups cadastradas.

A metodologia de níveis do Revive Negócio, detalhada neste trabalho, foi modelada para trabalhar com quatro diferentes tipos de usuários: o criador, responsável por preencher as informações da ideia, solução ou startup e acompanhar seu trajeto dentro da plataforma; o a consel hador, responsável por estudar a ideia e, caso aprove, direcionála para os parceiros; o Parceiro, responsável por contribuir com o desenvolvimento da ideia no aspecto apontado pelo aconselhadores; e o administrador, que é um membro da equipe idealizadora da plataforma, responsável por cadastrar novos usuários aconselhadores e parceiros.

Atualmente, a plataforma Revive Negócio está hospedado em um endereço online ${ }^{6}$ com acesso a todas as funcionalidades de forma gratuita. A plataforma já está sendo utilizada no cadastro de ideias e startups de diversos projetos da Secretaria de Desenvolvimento Econômico e Trabalho (SEDET) e da Secretaria de Ciência Tecnologia e Ensino Superior (SECITECE) do Estado do Ceará em parceria com outros órgãos públicos e privados, tais como Serviço Brasileiro de Apoio às Micro e Pequenas Empresas (SEBRAE), Aceleradora NINNA Hub, Hub Cumbuco, etc. Desde seu lançamento, em novembro de 2020, a plataforma já registra mais de 50 startups e 50 ideias cadastradas. A Tabela 1 apresenta as áreas com maior quantidade de ideias cadastradas, vale destacar que uma ideia pode pertencer a mais de uma área.

Tabela 1. Quantidade de ideias por área.

\begin{tabular}{|l|c|}
\hline Área & Quantidade \\
\hline Tecnologia da Educação e Comunicação & 20 \\
\hline Educação & 15 \\
\hline Agronegócio & 13 \\
\hline Turismo & 13 \\
\hline Saúde & 13 \\
\hline Energias Renováveis & 10 \\
\hline
\end{tabular}

O restante do trabalho possui a seguinte estrutura: a Seção 2 apresenta os trabalhos relacionados; a Seção 3 apresenta a plataforma Revive Negócio, sua metodologia e aspectos de implementação; por fim, a Seção 4 apresenta a conclusão.

\section{Trabalhos Relacionados}

O SEBRAE ${ }^{7}$ é uma entidade privada sem fins lucrativos com o objetivo de auxiliar pequenos negócios de todo o país. Criada em 1972, a entidade trabalha com a capacitação e promoção de desenvolvimento, sendo responsável pelo lançamento de vários programas

\footnotetext{
${ }^{6}$ Disponível em: http://hom.revivenegocio.com/

${ }^{7}$ Fonte: sebrae.com.br
} 
que incentivam a criação e crescimento de startups, tais como o Desafio Startup SEBRAE e StartupCE. O programa StartupCE oferece, aos empreendedores selecionados, um programa de pré-aceleração desenvolvido com metodologias atuais de desenvolvimento de negócios tecnológicos e de alto impacto no mundo. A principal motivação desse programa é transformar ideias inovadoras em negócios sustentáveis, com uma metodologia de capacitação imersiva onde o responsável pela ideia vivencia todas as fases de desenvolvimento de uma startup, com o acompanhamento de mentores ou profissionais especializados que irão compartilhar suas experiências. Todavia, os programas desenvolvidos pela SEBRAE atuam na gestão de negócios das startups, dessa forma, não possuem um grande foco em auxílio técnico de desenvolvimento. Em sua metodologia, o Revive Negócio fornece, além do auxílio de negócios, um auxílio técnico com profissionais atuantes na área.

A Universidade Federal do Ceará (UFC) lançou, em 2020, a Plataforma Colaborativa de Ações ${ }^{8}$, um site que serve de repositório para ideias de enfrentamento ao COVID-19. A plataforma colaborativa oferece ao usuário funcionalidades para listar todas as ações cadastradas, cadastrar novas e auxiliar as existentes com doação de materiais. A plataforma também ajuda na divulgação de sites com foco no combate e controle à doença, assim como também disponibiliza materiais educativos sobre como se adaptar às mudanças que ocorreram em diversas áreas durante a pandemia de coronavírus, como saúde e educação. Contudo, por conta da temática, a plataforma só aceita ideias de enfrentamento direto ao COVID-19, diferentemente do Revive Negócio que não possui essa condição. O Revive Negócio também se diferencia por conta de sua metodologia de apoio e desenvolvimento da ideia ou startup cadastrada, colocando o responsável em contato com empresas consolidadas da região.

O uso de plataformas para auxiliar em campanhas de publicidade e desenvolvimento de empresas e projetos está cada vez mais popularizado [Hervé and Schwienbacher 2018]. Plataformas como Kickstarter ${ }^{9}$, Indiegogo ${ }^{10}$ e Kickante $^{11}$ se popularizaram por trabalharem com financiamento do tipo crowdfunding. A Indiegogo cobra uma taxa de 5\% de cada investimento e se destaca por oferecer um suporte experiente e parcerias exclusivas, além de usar sua fama e influência como vantagem para promover publicidade para o amplo escopo de projetos que fazem parte da plataforma. Contudo, nenhuma das plataformas citadas oferece uma metodologia própria de auxílio no desenvolvimento da ideia com serviços gratuitos e sem taxas cobradas em cima dos investimentos.

\section{Revive Negócio}

\subsection{Metodologia}

A plataforma Revive Negócio aceita ideias em diferentes níveis de maturidade, como por exemplo ideias com ou sem documentação, ainda não testadas ou que já são produtos. Dessa forma, a plataforma poderá participar de todas as fases de desenvolvimento da ideia. O nível inicial de maturidade da ideia será um atributo da ideia que será alterado constantemente no decorrer de seu percurso nos sete níveis da plataforma.

\footnotetext{
${ }^{8}$ Fonte: http://bit.ly/acoescovidufc

${ }^{9}$ Fonte: https://www.kickstarter.com/

${ }^{10}$ Fonte: https://www.indiegogo.com/

${ }^{11}$ Fonte: https://www.kickante.com.br/
} 
Após o criador cadastrar uma ideia, o estado da mesma na plataforma será definido de acordo com os atributos status da ideia e status do processo. O status da ideia pode ser:

- Ideia Cadastrada: status inicial da ideia, quando o usuário criador preenche completamente suas informações no formulário de cadastro;

- Ideia em Aconselhamento: indica que a ideia foi selecionada por um usuário aconselhador para que seja encaminhada para as empresas parceiras de acordo com sua necessidade atual;

- Ideia Impulsionada: indica que a ideia passou pelos parceiros técnicos e de negócios e agora possui todos os requisitos necessários para se transformar em um produto.

Esse atributo (ou campo) será visível ao usuário criador para que o mesmo possa acompanhar o trajeto de sua ideia dentro da plataforma. Quando ocorrer uma atualização no status da ideia será enviado um e-mail para o usuário criador informando a nova situação de sua ideia.

O status do processo será visível a todos os tipos de usuários com exceção do criador, o mesmo é usado como indicador interno na plataforma para servir de guia aos outros tipos de usuários (aconselhadores, parceiros e administradores) sobre o que fazer em seguida com a ideia analisada. O status do processo pode ser:

- Ideia Cadastrada: status inicial da ideia, quando a ideia é encaminhada à lista de ideias a serem examinadas pelo aconselhador;

- Aconselhamento Grupo Técnico: indica que a ideia foi selecionada por um usuário aconselhador e será encaminhada a um parceiro de acordo com sua necessidade atual;

- Aconselhamento Parceiro: indica que a ideia está sendo auxiliada por um parceiro que atenda às suas necessidades atuais;

- Análise Comitê Estratégico: indica que a ideia já passou pelo auxílio dos grupos parceiros e está pronta para ser impulsionada;

- Ideia Impulsionada: indica que a ideia passou por todos os níveis da plataforma e agora possui todos os requisitos necessários para se transformar em um produto;

- Ideia Não Impulsionada: indica que a ideia não foi escolhida para aconselhamento por nenhum usuário aconsel hador;

- Reanálise: indica que a ideia deve retornar à lista de ideias do usuário aconselhador para uma reavaliação.

Para construção do fluxo da plataforma foi desenvolvido um diagrama de atividades que separa as etapas e funcionalidades de cada parte envolvida de maneira clara e intuitiva. Os atores do diagrama desenvolvido ${ }^{12}$ representam a própria plataforma e os tipos de usuários. Dessa forma, no diagrama, a plataforma é representada como "Revive Negócio", o usuário criador como "Criador", os a consel hadores formam o grupo "Parceiro Aconselhador", os parceiros compõe os grupos "Parceiro de Negócios" e "Parceiro Técnico", por fim, os administradores formam o "Comitê estratégico".

\footnotetext{
${ }^{12}$ Disponível em: https://cutt.ly/ohx6Qof
} 


\subsection{Níveis}

No primeiro nível, o criador, após ser cadastrado na plataforma, precisará concordar com os termos de uso da plataforma. Após esse passo, é apresentado ao usuário o formulário de cadastro da ideia, onde o mesmo deve preencher as informações da ideia que deseja cadastrar. Após concluído o cadastro, os atributos status da ideia e status do processo serão atualizados para Ideia Cadastrada e usuário criador recebe um e-mail de confirmação com protocolo gerado para a sua ideia.

Após a conclusão do primeiro nível, a ideia recém-cadastrada aparece na lista de ideias dos usuários aconselhadores, representantes do grupo Parceiro Aconselhador. No segundo nível, os aconselhadores poderão visualizar as informações das ideias e alterar seu status com base em sua viabilidade. Caso o aconsel hadores não aprove a ideia, o status do processo da mesma é alterado para Ideia Não Impulsionada. Caso o aconselhadores aprove, o status da ideia é alterado para Ideia Em Aconselhamento, o status do processo é alterado para Aconselhamento Grupo Técnico e um e-mail é enviado ao criador informando o novo status de sua ideia.

Ainda no segundo nível, após alterar os status da ideia e do processo e informado ao criador que sua ideia foi escolhida para aconselhamento, é necessário encaminhar a ideia para os grupos parceiros. Caso a ideia necessite de auxílio técnico, a mesma deverá ser encaminhada para o grupo Parceiro Técnico. Por fim, caso a ideia necessite de um projeto de negócio, deverá ser encaminhada ao grupo Parceiro de Negócios. Os parceiros são empresas (públicas ou privadas) de tecnologia cadastradas que se disponibilizam para ajudar os criadores de ideias da plataforma. Esse auxílio pode ser acontecer, por exemplo, disponibilizando funcionários para atuar como instrutores, conceder locais para serem usados como laboratório de desenvolvimento etc.

No terceiro nível encontram-se os parceiros da plataforma, especializados em diferentes auxílios oferecidos aos criadores. O grupo Parceiro Técnico, que contém os parceiros especializados em auxílio técnico, auxiliam na construção de um protótipo disponibilizando uma infraestrutura técnica ao Criador. Uma vez concluído, o parceiro emite um parecer técnico que deve ser anexado juntamente ao protótipo na documentação da ideia pelo Criador. O protótipo anexado será analisado nos níveis seguintes juntamente com as demais documentações anexadas.

Em seguida, o Parceiro Técnico auxilia o Criador na especificação técnica do projeto, ajudando na escolha e capacitação de tecnologias de desenvolvimento e no planejamento da etapa de desenvolvimento. Nesse nível, o Criador irá possuir um projeto técnico e deverá anexá-lo na documentação da ideia. Nesse projeto técnico, serão detalhadas as etapas de execução, metas e resultados esperados da proposta.

Ainda no terceiro nível, os instrutores do grupo Parceiro de Negócio analisam o pré-projeto e auxiliam com estratégias econômicas. Nesse nível, o Criador irá construir seu plano de negócios e anexá-lo na documentação da ideia. No projeto de negócio será discutida a viabilidade do projeto. Para isso, será feita uma análise de mercado que engloba o estudo de possíveis clientes, fornecedores e das necessidades do produto em geral. A geração do projeto de negócio também inclui a construção de um plano de marketing, para descrição do produto e seus serviços e estimativa de custos, e um plano financeiro, onde será discutida a viabilidade do produto, rentabilidade e estimativas de retorno de 
investimento.

No fim do terceiro nível, o status do processo é atualizado para Análise do Comitê Estratégico e o Parceiro Aconselhador deverá emitir um parecer informando que a ideia passou por todos os níveis anteriores. Feito isso, a ideia é encaminhada para análise do Comitê estratégico que irá emitir uma decisão final com justificativa se a ideia deverá ser impulsionada ou não. Caso a decisão do comitê seja sim, o status da ideia e status do processo serão alterados para Ideia Impulsionada e a ideia será encaminhada para o quarto nível, onde será transformada em uma startup. Caso a decisão do comitê seja não, a justificativa dada deverá ser analisada. Caso seja decidido que a ideia precisa de uma reanálise, o status do processo será alterado para Reanálise, o status da ideia será alterado novamente para Ideia Cadastrada e a ideia retornará para o Segundo Nível. Caso seja decidido que a ideia não precisa de uma reanálise, o status da ideia retornará para Ideia Cadastrada e o status do processo será alterado para Ideia Não Impulsionada.

No quarto nível, caso a ideia já não seja pertencente a uma startup, o Revive Negócio irá direcionar o Criador para os parceiros de Aceleração. Esses parceiros serão responsáveis por instruir o usuário a preencher toda a documentação necessária para criar uma startup, esclarecendo quaisquer dúvidas do Criador.

No quinto nível, o Revive Negócio irá aplicar seus recursos publicitários naquela startup, colocando-a em contato com os parceiros do grupo Parceiro de Aceleração. Por sua vez, o grupo de aceleração é especializado em campanhas publicitárias e será responsável por auxiliar a startup a por em prática suas estratégias de marketing desenvolvidas no terceiro nível.

No sexto nível, o criador irá buscar investimentos para sua startup. Assim, é possível que essas colaborações venham de instituições tradicionais de financiamento ou até de empresas parceiras da plataforma. Contudo, está sendo estudada a implementação de funcionalidades de crowdfunding para possibilitar a obtenção de investimentos de fontes alternativas.

Crowdfunding é um modelo de financiamento que permite que o público (crowd) participe do financiamento (funding) de projetos que acharem relevantes. Esse modelo permite que pequenos empreendedores ou startups consigam financiamento de vários investidores, oferecendo recompensas que podem compreender desde produtos personalizados, como, por exemplo, camisas e cartas de agradecimento até ações da companhia [Mollick 2014].

Dessa forma, com essa nova funcionalidade, o usuário Criador poderá iniciar uma nova campanha de crowdfunding. Para isso, o mesmo deverá concordar com todos os termos da plataforma e informar as características daquela campanha, como meta, duração, etc. Vale lembrar que essa funcionalidade só será acessível por startups com ideias com status Ideia Impulsionada. Inicialmente, o Revive Negócio irá trabalhar apenas com equity-based crowdfunding, onde a contribuição dos investidores é monetária.

As campanhas seguirão o modelo "tudo ou nada", visando a proteção dos investimentos em campanhas que não concluíram suas metas. Esse modelo de campanha transforma os investimentos inicialmente em promessas, as quais devem ser cumpridas uma vez que a campanha tenha atingido a meta. Isso evitará o trabalho de devolver os investimentos a todos os participantes da campanha. Os possíveis investidores serão as 
empresas parceiras da plataforma e demais usuários.

Os investimentos poderão ser de qualquer quantia e as recompensas oferecidas serão de responsabilidade do dono da campanha. Dessa forma, para garantir que os investidores recebam as recompensas prometidas e que os mesmos cumpram suas promessas de contribuição à campanha, serão regidos documentos que devem ser concordados por ambas as partes para efetuar a participação. Como o Revive Negócio possui parceiros em diversas áreas, essa documentação poderá ser redigida por profissionais da área que são colaboradores da plataforma. Com isso, será possível evitar ou minimizar problemas que possam existir, garantindo que os envolvidos tenham ciência de seus direitos e deveres no decorrer da campanha. As demais características das campanhas de crowdfunding, como limites de tempo e meta, estão em fase de planejamento e serão acrescentadas em versões futuras do planejamento da plataforma.

No sétimo e último nível, é abordada a questão da responsabilidade social. Assim sendo, o usuário recebe um convite para participar do conselho interno do Revive Negócio. Esse conselho é dividido em dois focos principais, melhoria do Revive Negócio e apoio a campanhas publicitárias que incentivam, por exemplo, a criação de startups. O Revive é uma plataforma em constante mudança, esse conselho interno é responsável por tomar decisões relacionadas a sua governança e futuras funcionalidades.

\subsection{Aspectos de Implementação}

A plataforma Revive Negócio utiliza o modelo arquitetural Representational State Transfer (REST). Além de auxiliar na integração entre o cliente (front-end) e o servidor (backend), o modelo REST permite a interoperabilidade entre sistemas que desejam compartilhar dados. O front-end pode ser entendido como a parte visível ao usuário, ou seja, a interface responsável por apresentar ao usuário todas as funcionalidades que estão à seu alcance de forma intuitiva e agradável [Faniran et al. 2000]. O back-end é a parte não visível ao usuário que controla o acesso aos dados e disponibiliza as funcionalidades que podem ser consumidas pelo front-end [Verborgh and Dumontier 2016].

A arquitetura do Revive Negócio é apresentada na Figura 1. O Revive Negócio usa o serviço Virtual Private Cloud (VPC) da Amazon Web Services ${ }^{13}$ (AWS) para construir uma rede privada dentro da nuvem de dados do AWS (AWS Cloud) e assim utilizar seus recursos. Para controlar o tráfego na aplicação e aumentar a disponibilidade e a tolerância a erros é usado um Elastic Load Balancing (ELB), responsável por distribuir as cargas de trabalho para vários recursos computacionais. A interface (front-end) e o servidor (backend) estão armazenados em instâncias do serviço Elastic Computer Cloud (EC2). Essas instâncias são computadores virtuais alugados para rodar aplicações de computador dos usuários na AWS Cloud. Os documentos estão sendo armazenados em uma instancia do Simple Storage Service (S3), um serviço utilizado para armazenamento de objetos.

O front-end e o back-end consultam uma instância da Kumu ${ }^{14}$, uma plataforma de visualização de dados utilizada para mapear e visualizar as relações entre as entidades da plataforma, como Startups e empresas parceiras. O back-end também consulta uma instância na nuvem de dados do mongoDB (MongoDB Cloud) onde está armazenada a base de dados do Revive Negócio.

\footnotetext{
${ }^{13}$ Fonte: aws.amazon.com/pt/products/

${ }^{14}$ Fonte: https://kumu.io/
} 


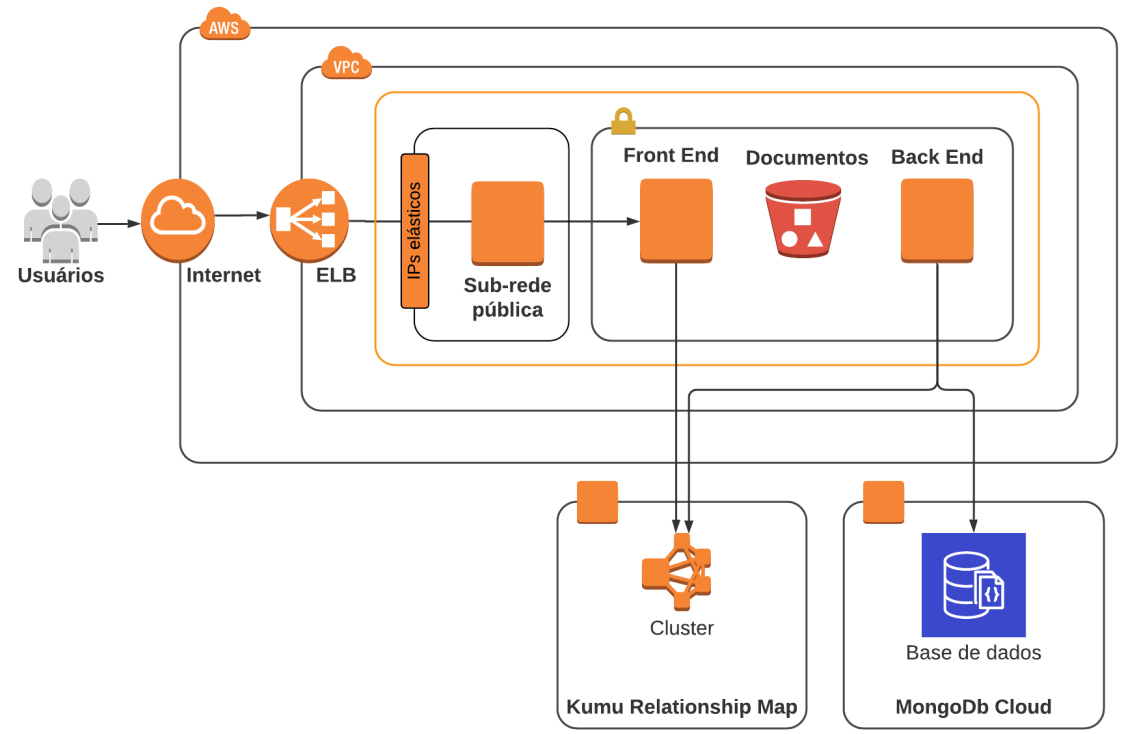

Figura 1. Arquitetura do Revive Negócio.

Cada tecnologia escolhida para o Revive Negócio foi selecionada com base em sua popularidade e suporte oferecido pelas comunidades de programação. A base de dados foi construída com o MongoDB, uma tecnologia para criação de bases de dados Not only SQL (NoSQL), isto é, modelos não-relacionais onde o armazenamento é baseado em modelos que podem ser otimizados para armazenar tipos específicos de dados [Jatana et al. 2012]. O back-end foi construído utilizando Node.js ${ }^{15}$, um ambiente para desenvolvimento de back-end baseado na linguagem de programação JavaScript. O Node.js foi escolhido por conta de sua alta flexibilidade e escalabilidade, capazes de aumentar assim a produtividade da equipe de desenvolvimento e facilitar a integração com serviços em nuvem que possuem suporte a aplicações desenvolvidas com essa tecnologia. A principal linguagem do back-end será TypeScript, dessa forma, foi escolhido o Framework NestJS ${ }^{16}$ devido ao seu grande suporte à linguagem. Para construção do front-end foi utilizado o Framework Vue.js juntamente com a linguagem de programação JavaScript. famoso por sua baixa curva de aprendizado e fácil configuração, o Vue.js está na lista de Frameworks mais famosos do mundo, pois permite a construção de aplicações complexas, com alta performance e uma arquitetura enxuta.

\section{Conclusão}

O Revive Negócio é resultado de um trabalho multidisciplinar nas áreas de computação e de gestão empreendedora, à medida que sua metodologia de sete níveis, detalhada na Seção 3, dá foco às principais funcionalidades disponibilizadas pela plataforma aos seus usuários. A plataforma já se encontra operacional no âmbito do Governo do Ceará, onde ambiciona ser o componente de entrada do ecossistema de inovação do Estado. Isso traz enorme beneficio à comunidade considerando que, enquanto repositório, o Revive Negócio dá visibilidade às ideias e startups cadastradas, além do impulsionamento proposto pela sua metodologia.

\footnotetext{
${ }^{15}$ Fonte: nodejs.org

${ }^{16}$ Fonte: nestjs.com
} 
O Revive Negócio pretende contribuir para o enfrentamento mais eficiente de problemas subsidiando a tomada de decisões adequadas, uma vez que uma retomada inteligente da economia no redesenho atual deve ser acompanhada de ações de curto e longo prazos, daí ser imprescindível a participação efetiva da sociedade. Com uma metodologia inovadora, em seu sétimo nível, descrito na Seção 2, o Revive Negócio desestimula a ideologia do individualismo, provocando reflexões sobre colaboração em seus usuários. Para a construção de um bom ecossistema de tecnologia, é necessário existir uma boa relação entre as empresas locais, o conceito de responsabilidade social e de oportunidades para os jovens.

Uma vez totalmente implantada, a plataforma Revive Negocio representará um avanço no sistema de gestão do Estado pelos benefícios advindos com a construção de um ecossistema de inovação, com vantagens não só aos produtores de ideias e startups cadastradas mas também pela realimentação que esse novo cenário de atores promoverá no desenvolvimento socio econômico no Estado.

\section{Agradecimentos}

Os autores agradecem ao Secretário Executivo da SEDET, Júlio Cavalcante, e às demais instituições envolvidas na concepção, desenvolvimento e transformação do Revive Negócio em um ecossistema de Inovação do Ceará: Instituto Iracema Digital, Aracati Digital, APSV Advogados, SECITECE, ETICE e IFCE.

\section{Referências}

DA COSTA, G. L. S. (2020). A pandemia do novo coronavírus e os impactos na economia e nas relações trabalhistas no brasil. ETIC-ENCONTRO DE INICIAÇÃO CIENTÍFICA-ISSN 21-76-8498, 16(16).

Faniran, O., Love, P., and Smith, J. (2000). Effective front-end project management-a key element in achieving project success in developing countries. In Proceedings of Construction Development Conference.

Hervé, F. and Schwienbacher, A. (2018). Crowdfunding and innovation. Journal of economic surveys, 32(5):1514-1530.

Ho, C. S., Chee, C. Y., Ho, R. C., et al. (2020). Mental health strategies to combat the psychological impact of covid-19 beyond paranoia and panic. Ann Acad Med Singapore, 49(1):1-3.

Jatana, N., Puri, S., Ahuja, M., Kathuria, I., and Gosain, D. (2012). A survey and comparison of relational and non-relational database. International Journal of Engineering Research \& Technology, 1(6):1-5.

Mollick, E. (2014). The dynamics of crowdfunding: An exploratory study. Journal of business venturing, 29(1):1-16.

PASINI, C., Carvalho, E., and Almeida, L. H. C. (2020). Educação híbrida em tempos de pandemia: algumas considerações. Observatório Socioeconômico da COVID-19.

Verborgh, R. and Dumontier, M. (2016). A web api ecosystem through feature-based reuse (2016). 